\title{
LEX MERCATÓRIA: PODER CONFLITUAL OU PODER CONSENSUAL COM A ORDEM JURÍDICA ESTATAL?
}

\section{LEX MERCATORIA: CONFLICTUAL POWER OR POWER CONSENSUS WITH STATE LAWS?}

Fabiano Derussi

\section{RESUMO}

Este trabalho explora a Lex Mercatória enquanto uma forma de pluralismo jurídico, bem como de poder. Inicialmente aborda-se da antiga à nova Lex Mercatória. Posteriormente, é analisada como poder conflitual ou consensual ante a ordem jurídica estatal, chegando-se ao objetivo de entender que forma de poder ela se caracteriza. Por meio do método de pesquisa bibliográfico chegou-se à conclusão de que a forma de poder que a Lex Mercatória assume, depende das particularidades de cada Estado e se dá de forma preponderantemente conflitual ou preponderantemente consensual, não existindo uma forma pura de poder.

Palavras-chave: Lex mercatória, Pluralismo jurídico, Poder

\begin{abstract}
This paper explores the Lex Mercatoria as a form of legal pluralism and power. Initially it addresses from the old to the new Lex Mercatoria. Subsequently, it is analyzed as conflictual or consensual power before the state law, reaching the goal of understanding how power it is characterized. Through bibliographical research method came to the conclusion that the form of power that Lex Mercatoria takes depends on the particularities of each country and gives predominantly conflictual way or predominantly consensual and there is not pure form of power.
\end{abstract}

Keywords/: Lex mercatoria, Legal pluralism, Power

\footnotetext{
${ }^{1}$ Professor titular de Direito Civil da Universidade Comunitária da Região de Chapecó, Especialista em Direito Civil e Processo Civil com ênfase Empresarial pela Universidade do Oeste de Santa Catarina, Unoesc - Santa Catarina, SC, Brasil. E-mail: indexlaw.ojs@ hotmail.com
} 


\section{INTRODUÇÃO.}

O estudo que se apresenta traz uma discussão sobre o poder exercido pelos atores internacionais privados por meio da Lex Mercatória quando comparado com o poder estatal na produção normativa do Direito Econômico Internac ional, com enfoque na classificação do poder conflitual e consensual.

Inicialmente, aborda-se a antiga Lex Mercatória desde as suas origens, fazendo-se um resgate histórico dos seus primórdios na civiliz ação antiga, posteriormente adentrando-se à Idade Média, berço no qual se desenvolveu mais in tensamente, indo até o surgimento do Estado Moderno, momento em que desaparece.

Posteriormente, é tratado do fenômeno da globalizaç ão do comércio e do capital, objetivando entender o fenômeno que propiciou o res surgimento de um direito paraestatal o qual foi denominado de nova Lex Mercatória , já que as fronteiras dos estados estão cada vez mais esburacadas em razão da limitação do alcance d e seu direito positivo tradicional.

Em seguida, fala-se sobre o pluralismo jurídico e suas facetas, já que este enfraquecimento dos estados acaba por permitir que tais ordenamentos paralelos surjam, bem como o próprio Estado é levado ao reconhecimento de alguns deles, seja de forma consensual ou não.

Por fim, a discussão gira em torno de qual categori a de poder a Lex Mercatória se enquadraria frente ao ordenamento estatal: Poder consensual ou poder conflitual? Assim, o problema de pesquisa proposto reside em saber quando a Lex Mercatória é um poder consensual e quando é um poder conflitual com a ordem jurídica estatal em geral.

Justifica-se o presente enfrentamento para fins metodológicos, na compreensão da posição que a Lex Mercatória ocupa em relação ao ordenamento estatal; para a me lhor compreensão do fenômeno contemporâneo do pluralismo jurídico; de como se dá o entrosamento entre o poder dos diversos ordenamentos jurídicos e como o conflito pode ser afastado pelas partes.

O método investigativo foi o bibliográfico, com coleta de informações em obras doutrinárias e artigos científicos. O tipo da pesquisa e a básica, pois visa a produzir novos conhecimentos, sem uma aplicabilidade imediata prevista, mas, também, será do tipo qualitativa, comprometida apenas em explicar fenôme nos jurídicos que ocorrem no mundo do comércio internacional. 


\section{LEX MERCATÓRIA : PODER CONFLITUAL OU PODER CONSENSUAL COM A ORDEM JURÍDICA ESTATAL.}

\subsection{LEX MERCATÓRIA E SUAS ORIGENS.}

Desde que o homem passou a viver em sociedade, os contratos passaram a existir. Logicamente não da forma que se apresentam atualmen te, mas o consenso entre duas pessoas para o alcance de um objetivo comum, apresenta o núcleo do conceito de negócio jurídico encampado pelas modernas teorias civilistas.

O ponto interessante é que na antiguidade os contratos inicialmente ganhavam contornos locais, na própria aldeia ou comunidade. Mas, nas civilizações próximas a rios navegáveis, o homem desenvolvendo suas técnicas denavegação começa a comerciar com outras comunidades, incrementando assim a economia local com produtos de outras regiões.

A sistemática é a mesma da troca, contudo, agora asnecessidades são supridas com bens de outras civilizações os quais por questões g eográficas ou técnicas, não conseguem ser supridas pela produção local.

Strenger (1996) relata algumas civilizações antigas que comerciavam internacionalmente e que possuíam normatização para tais empreitadas. Os fenícios destacaram-se à sua época justamente por serem os percussores da navegação. Já naquela época aquela civilização desenvolveu o que se chamou de Lex Rhodia de jactu, regulando na alta antiguidade diversas questões ligadas ao comércio internacional, especialmente os contratos.

Na Grécia Antiga e Roma também já existia comérciointernacional, embora ainda não recebesse esta denominação. Estas civilizações dominavam as águas do Mar Mediterrâneo com suas expedições marítimas e assim acabavam estabelecendo relações externas aos seus domínios, consequentemente, faziam contato com culturas diferentes das quais estavam habituados.

A civilização helenística foi tão avançada que segu ndo Strenger (1996) pode ser comparada com as revoluções comerciais e industriai s da era moderna. Dentre as várias causas apontadas, estavam as conquistas alexandrinas que propiciaram uma área de comércio que ia do Rio Nilo à Índia; Com a abertura comercia 1, houve elevada entrada de ouro e prata do Império Romano, criando-se assim uma cadeia de nvestimentos e também de especulação; 
E por fim, os governos da época passaram a incentivar o comércio e a produção, com o fito de incrementar suas receitas.

Todos estes fatores reunidos acabaram por acarretar uma série de consequências de cunho jurídico, especialmente em matéria de regulação do capital e do comércio, sendo que os governos tornaram-se um verdadeiro capitalista e também empresário. Já existia ali uma política monetária "internacional", baseada no ouro e na prata. Também existiam bancos, geralmente de propriedade dos governos, os quais financiavam as viagens dos mercadores.

O povo Ptolomeu também teve contribuições neste cen ário de mercancia internacional na antiguidade, pois recorreram aos grandes geógrafos da época e assim conseguiram novas rotas marítimas, consequentemente, conquistaram importantes mercados.

Relata Strenger (1996, p. 56) que no porto de Alexandria circulavam bens de várias naturezas e diferentes localidades, como "especiari as da Arábia, cobre do Chipre, ouro da Abissínia e da Índia, estanho da Bretanha, elefantes e marfim da Núbia, prata do norte Egeu e da Espanha, finos tapetes da Ásia Menor e até seda da China.”

O império Romano, por sua vez, era uma civilização que possuía um aparato jurídico extraordinário para sua época, inclusive com algunsinstitutos de Direito Civil presentes até os dias atuais em ordenamentos jurídicos de vários estados. Já disciplinava o comércio internacional por meio do Jus Gentium ou direito das gentes, um grande instituto jurídico que permitia estrangeiros invocar o Direito Romano especialmente na seara comercial, o que era um avanço para à época. Objetivava, assim, fomentar a circulação de riquezas para fora de suas fronteiras, fenômeno muito semelhante ao que o corre na atualidade.

Mas, após as invasões bárbaras, o Império Romano entra em decadência e, de modo geral, a Europa passa por sérias instabilidades políticas e jurídicas, iniciando-se, assim, um período extremamente inseguro ao comércio. Dá-se início do período histórico conhecido como Idade Média.

Com a queda do Império Romano, para resistir os bárbaros a organização social teve que modificar-se substancialmente. As cidades passaram a viver cada vez mais isoladas e organizadas em feudos, consequentemente, passando a ter um regramento próprio e descentralizado. Ressalta-se que apesar de inseguro, foi uma oportunidade ímpar para o comércio desvencilhar-se das amarras da burocraciaromana. E isto foi um verdadeiro estopim para o surgimento de um novo direito, que acabou levando a denominação de Lex Mercatória ou, também, Lei Mercante. 
Ocorre que apesar das mudanças dos paradigmas polí tico e jurídico das cidades, mesmo intimidado o comércio não desapareceu. Pelo contrário, acabou intensificando-se, especialmente após acontecimentos como o das cruzad as. Contudo, agora revela-se sob nova roupagem jurídica.

Surge durante a Idade Média as corporações de class e, justamente para organizar e disciplinar as atividades indispensáveis à manutenção das cidades. Dentre estas corporações, surge a dos mercadores, que era segundo Strenger (1996), quase que um pequeno estado protetor da classe.

As corporações além de editar normas, também tinham a função judicante perante seus membros. Os julgamentos ocorriam entre os próp rios pares inscritos para tal fim. Dentro destas corporações já existia o princípio do duplo grau de jurisdição, pois havia a possibilidade de recurso para novos juízes dentre os membros da corporação inscritos para tal fim.

Cordeiro (2008) relata que as corporações possuíam patrimônio próprio, composto por doações de seus sócios, tinham como objetivo pr oteger e dar assistência a seus membros e, posteriormente, passaram a dar, também, assistência jurisdicional. Tinham, assim, três funções: Primeiramente a função política, na defesa de seus membros, na defesa da honra da própria corporação e na manutenção da paz e seguran ça; Posteriormente, tinha função executiva na observância e cumprimento de seus esta tutos, podendo, inclusive, aplicar multas aos infratores, excluir membros, etc.; E, por fim, tinham a função jurisdicional para solucionar controvérsias entre seus membros, conforme anteriormente relatado.

Percebe-se, assim, que naquilo que os governos das cidades eram omissos em regulamentar, as classes sociais organizadas o faziam, de modo que certos costumes e regras comerciais passaram a ser amplamente aceitos por mercadores de diversas cidades e, assim, surge um direito paralelo e descentralizado ao poder local, o qual ficou conhecido como Lex Mercatória .

Este novo direito, assim por dizer, cria uma então inédita integração jurídica do Direito Comercial, independente de espaços geográficos, como ocorreu com a disciplina do crédito e de alguns tipos sociais a exemplo da comenda (GLITZ, 2012).

Também, pode-se perceber que o poder durante a Idade Média estava bastante fragmentado, sendo que as corporações de ofício, co mo a dos mercadores, apesar de não 
dispor de espadas, tampouco de tanques, possuíam um poder ideacional muito forte sobre a classe que representavam, fator que inclusive contribuiu para a formação da chamada classe burguesa, que se não foi o estopim, foi o próprio b arril de pólvora para a implantação de um novo sistema, o qual dá início à chamada Idade Moderna.

Tratava-se de um modo de governança especial, o qua 1 Mathias Koening-Archibugi apud Olsson (2007) trata em tempos atuais de "transnaci onalismo global delegado", onde há uma mínima publicidade, ou seja, os estados ou os governos oficiais estão praticamente ausentes; Há uma máxima delegação, pois recebe um randeg número de atribuições pelos membros que à compõe; E, por fim, há uma máxima inclusividade, pois difundia-se à todos os comerciantes e/ou mercadores.

Este período da Idade Média, conhecido como período negro da História, a bem da verdade não foi tão negro assim, pois apesar de lon go e inseguro, foi terreno fértil para o surgimento de diversos fenômenos sociais e jurídico s como foi o caso da Lex Mercatória.

Ressalta-se que para fins didáticos, este direito horizontal que tratava do Direito Comercial compreendido durante a Idade Média, fica doravante denominado de antiga Lex Mercatória . Isso porque em determinado momento esta forma plural de ordenar a sociedade, praticamente desaparece.

\subsection{NOVA LEX MERCATÓRIA E SUAS FONTES.}

Contudo, com o fortalecimento econômico da classe b urguesa, corroborado pelo aperfeiçoamento das técnicas de produção, acompanha do pelas novas descobertas científicas e desmistificação de alguns dogmas religiosos que imp regnavam todo aquele período histórico, acabou por demonstrar que aquele sistema político baseado em feudos e monarquias privilegiadas, já não atendia os interesses do capital.

Inicialmente, o embrião do Estado Moderno passa pel a centralização do poder em uma monarquia absolutista, vitalícia e hereditária,que também passa a se tornar territorial. Este processo deu-se lentamente durante a Idade Média, especialmente pela presença forte da religião na consciência das pessoas, o príncipe era um ser ungido por Deus, por isso merecia o respeito de seus súditos.

Mas, com acumulação primitiva do capital, seja na a gricultura, indústria ou comércio, o ócio das elites monárquicas e eclesiásticas cai de moda (MONDAINI, 2005). Desta forma, somente uma revolução poderia libertar a mão de obra, o consumo, e 
consequentemente, o capital. Este movimento revolucionário iniciou-se na Inglaterra e ficou conhecido como Revolução Inglesa, expandiu-se para os Estados Unidos da América, culminando com a revolução Americana, e finda na Fr ança com a Revolução Francesa.

Estas revoluções marcaram o fim do Estado de submis são Hobbesiano, e implantaram o início do Estado Liberal contratualista de Locke (MONDAINI, 2005). Dá-se o início, assim, dos fundamentos do Estado Moderno, marcado pela liberdade e igualdade, embora estas possam ser bastante relativizadas em cada momento histórico.

Contudo, embora o novo momento fosse emblemático para um novo sistema social e político predominantemente capitalista, nem tudo saiu perfeito. Conforme o mesmo autor, o poder instituído pelo estado moderno não tinha outr a função a não ser preservar e proteger a propriedade privada. A união entre os homens por me io de um contrato social seria unicamente proporcionar a segurança desejada à prop riedade e ao capital.

Mas para que isso ocorresse, foi necessário que se delegasse aos governos o monopólio normativo, bem como o monopólio da violência necessária à manutenção do sistema, fato que foi chamado de soberania - um pod er amplo que não se submeteria a nenhum outro. Essa seria a marca dos Estados Nações .

Então, se neste novo cenário a propriedade e o capital restariam protegidos, por outro lado surgem outros inconvenientes o qual os contratualistas não previram. Embora há uma centralização do poder no Estado, esta ideologia li beral burguesa dissemina-se pelo mundo, fazendo surgir diversos Estados, cada um soberano por si e em seus territórios, culminando em grande diversidade de poderes, cada qual com sua cultura social e jurídica própria, tipicidades de cada povo.

Se há um ganho em termos de direitos de primeira, egundas e terceira gerações, proporcionando assim a manutenção do sistema de con sumo do capitalismo, por outro, há diversidade de estados legiferantes sobre todas as matérias que entenderem ser de seu interesse, calcados em seu poder soberano de decidir o futuro de seu povo, acaba por trazer novas incertezas para o comércio internacional.

Neste período inicial do Estado moderno, há quem afirme que a antiga Lex Mercatória desaparece, e que de fato, a depender do ponto de vista da observação, aquilo que existia desde a época das corporações de ofício já não se identifica com os fenômenos sociais da modernidade. 
Assim, encarrando como desaparecida a antiga Lex Mercatória, restam apenas os estados regulando o comércio internacional por meiode tratados e convenções internacionais, normas internas de Direito Internacional, etc. É o predomínio do que a doutrina chama de monismo jurídico, ou seja, somente o estado como fonte produtora do direito.

Bedin (2001, p. 176) explica que "articulada dessa forma, a sociedade internacional moderna vai-se definindo como uma sociedade tipicamente interestatal, em que estarão presentes, pelo menos inicialmente, apenas os Estados soberanos.” E, dentre a classificação dos atores da sociedade internacional, os Estados seriam o principal deles. Ressalta-se que atualmente este quadro mudou significativamente.

Mas, nem por isso o comércio internacional desaparece. Isso porque ele parece ser um poder autônomo, como a mão invisível do mercado identificada por Adam Smith (1996) em sua célebre obra Riqueza das Nações. Embora com dificuldades, com incertezas quanto a normatividade a ser aplicada sobre os contratos celebrados, os mercadores continuam a comerciar, e com incentivos dos próprios estados, $\mathrm{j}$ á que este tipo de atividade é de interesse comum.

Entretanto, a mais recente criação da modernidade, o Estado, já nos seus primeiros séculos de existência apresenta algumas patologiasas quais não consegue diagnosticar. A maioria delas, decorrentes dos efeitos da globalização econômica, intensificada principalmente após a Segunda Guerra Mundial e acel erada com o fim da chamada Guerra Fria (IANNI, 1996).

A globalização enquanto fenômeno social e complexo é de difícil abordagem em todas as suas facetas. Desta forma, o presente estudo irá se restringir à globalização da economia, que teve contribuição direta e fundamenta 1 pelo avanço tecnológico da sociedade, especialmente das comunicações.

Com o fenômeno da globalização, surgiram também as empresas multinacionais as quais organizam-se em rede em diversos espaços soci ais espalhados pelo globo. Desta forma, o capital se torna fluído, transitando pelas fronteiras nacionais quase que instantaneamente. Assim, os investimentos especulativos feitos em determinado Estado podem ser imediatamente retirados, deixando as economias nacionais vulneráveis as crises econômicas, que agora também tomam proporções globais. 
Para Bedin (2001, p. 331), a globalização "produz u ma surpreendente redefinição das noções de tempo e, especialmente, de espaço, conduz indo a uma diminuição das distâncias e tornando instantâneo qualquer acontecimento em qual quer lugar do planeta".

Diante de tais fenômenos, algumas teorias surgem pa ra explicar o que acontece no mundo globalizado, entre elas, as teorias da dependência e da interdependência das nações .A teoria da dependência parte da ideia de que algunsEstados são extremamente dependentes de outros, ou seja, não conseguem manter seu equilíbri o econômico apenas com a economia interna. Já a teoria da interdependência, por outrolado, vê no mundo globalizado uma ausência de Estado autossuficientes de si, alheiosas crises econômicas globais.

Da mesma forma que a globalização permitiu o fluxo do capital entre Estados, o comércio internacional também intensificou-se sensivelmente nos dois últimos séculos. Houve um intercâmbio de culturas sociais e jurídica s, que fez o monismo jurídico dos Estados ficarem fragilizados, surgindo sistemas jurídicos paralelos aos estatais para regulamentar setores muito específicos do comércio internacional.

Esta quebra de paradigmas dos Estados pela globalização tem como consequência um movimento de natureza privada, mas composta por diversos atores, que busca facilitar o comércio internacional, utilizando-se da uniformização e harmonização do direito aplicável aos contratos, bem como da criação de órgãos privad os de julgamento, que atuam independentemente da estrutura estatal, já que esta mostra-se estanque e carregada de incertezas jurídicas ao comércio global.

A este fenômeno decorrente da globalização, foi den ominado de nova Lex Mercatória, já que guarda certa semelhança com o comércio queocorria durante a Idade Média, onde os mercadores, organizados em corporaçõ es, eram a fonte de seu próprio direito e os juízes de seus litígios comerciais, utilizando como base um direito marcado pelos usos e costumes do comércio.

Então, seria a nova Lex Mercatória, definida por Baptista (2010, p. 63) o "conjunto de princípios, instituições gerais e regras com ori gem em diversos focos, e que se caracterizam por serem inspiradas e voltadas aos relacionamentos dos operadores do comércio internacional."

Dentro da solução de problemas do comércio internacional, Strenger (1996, p. 147) a define como "um conceito definitivo e único para exprimir o que se passa no comércio 
internacional e justificar as formulas peculiares que são ali aplicadas [...] sem necessidade de servir-se dos instrumentos legais oferecidos pelos regimes estatais."

Assim, a nova Lex Mercatória é um legítimo direito dos mercadores, não só por s er à eles destinado, mas, também, por ser por eles criado, de acordo com suas necessidades e costumes amplamente reconhecidos no meio em que fazem parte.

Dentre as organizações que estudam, preparam e edit am normas e costumes internacionais, pode-se citar como exemplo o Instituto Internacional para Unificação do Direito Privado - UNIDROIT. Também, outra importante fonte das normas do comércio internacional, seria a jurisprudência arbitral internacional, especialmente a da Câmara Internacional de Comércio - ICC.

O UNIDROIT em verdade trata-se de uma organização intergovernamental internacional, composta por estados nações e também por grupos de juristas de diferentes nacionalidades escolhidos por méritos pessoais, e não por qualquer tipo de indicação governamental (GAMA JR., 2006). São estes juristas que promovem estudos sobre a solução de problemas que lhes são postos. Ao todo já formaeditados mais de 70 trabalhos, dentre eles, leis modelos, princípios gerais aplicáveis aos comércio internacional e minutas de tratados e/ou convenções internacionais.

Já a ICC, é uma associação de empresários de todo omundo, cujo objetivo é fomentar a abertura do comércio e da economia de mercado. Os fundadores desta organização internacional privada, denominavam-se à época de “m ercadores da paz”. Sua fundação ocorreu em 1919 e desde então, está sediada em Paris, na França.

A ICC conta atualmente com associações empresarias de 130 países, possui escritório regionais em outros 90 estados e possui cerca de 6,5 milhões de empresas integrantes de sua rede. Além da sua jurisprudênciaarbitral, é órgão consultivo da ONU.

\subsection{PLURALISMO JURÍDICO NA ATUALIDADE}

Como visto, apesar do Estado deter o monopólio da p rodução oficial do direito, não consegue regular tudo. Em razão dos efeitos da glob alização, a rapidez das mudanças por ela trazidos acabam tornando o estado quase que obsoleto em sua função normativa, especialmente quando a regulação diz respeito à que stões comerciais internacionais, criandose, assim, terrenos propícios ao surgimento de sistemas jurídicos paralelos aos estatais. 
O fato é que o estado enfraqueceu em sua função normativa, e em razão disso, Wolkmer (2001, p. 151) esclarece que "as fontes clássicas do monismo estatal determina o alargamento dos centros geradores de produção juríd ica mediante outros meios normativos não convencionais", pois a necessidade não espera o Estado.

Assim, a tradicional ideia monista de que somente o Estado é produtor de direito e que no interior de um Estado exista apenas um ordenamento jurídico, passa a ser contestada pela teoria do pluralismo jurídico, em que considera que o direito emana de diversas fontes, não se restringindo somente as estatais, sendo poss ível a existência de mais de um ordenamento jurídico no corpo de um mesmo Estado.

Realmente, na seara do comércio internacional, a Lex Mercatória seria um desses sistemas paralelos ao estatais, embora há quem afirme ser um sistema contrário ao estatal e há quem afirme que seja um sistema complementar ao estatal. Ainda há uma corrente que nega a própria existência deste direito horizontal, mas, no presente estudo tal hipótese não será objeto de análise.

Continuando o raciocínio, Coelho (2001, p. 61) expressa que "O direito positivo passa assim a conviver com um direito paralelo que também pode ser considerado positivo, eis que suas regras são dotadas de até maior efetividade que as dos estados nacionais.” Um exemplo do que o autor afirma, está calcado na arbitragem internacional, onde menos de dez por cento das sentenças arbitrais necessitam ser le vadas à execução, a grande maioria delas são cumpridas voluntariamente.

Percebe-se, assim, que tais sistemas jurídicos paralelos aos estatais, possuem força normativa eficaz, logo, são fontes de poder. Assim, o velho paradigma de que apenas o Estado é fonte produtora do direito, resta claramente superada, e que negar ordenamentos paralelos aos estatais, seria negar o próprio sistema jurídic o.

Acontece que àquela tradicional estrutura hierárquica e vertical de leis, cede lugar a uma "estrutura circular e articulada, uma estrutura horizontal de normas de conduta social emanadas de centros diferenciados de poder e decisã o, além do Estado.” (COELHO, 2001, p. 74).

Arnaud (1999), complementa este raciocínio afirmando que o fenômeno da globalização contribuiu em muito para deslocamento das tradicionais fontes do direito para os poderes privados econômicos. Também percebe uma maior tomada de decisões com base em valores advindos do sistema econômico ou técnico científico. Sem contar ainda, com o 
crescente uso de cartas de intenções, códigos de bo m comportamento, etc., os quais são conhecidos como fontes "soft" do direito.

Contudo, acrescenta que o recuo do Estado demandou uma contrapartida, sendo ela a participação do setor público na criação privada do direito. Uma espécie de associação do setor público privado na criação normativa de inter esse econômico, afinal, a economia é interesse comum.

Realmente, este fenômeno também pode ser verificado sobre a nova Lex Mercatória . Percebe-se que nas principais fontes privadas de normas de direito comercial internacional, o Estado está envolvido. O próprio UNIDROIT trata-se de uma organização intergovernamental. Da mesma forma acontece com a UNCITRAL - Comissão das Nações Unidas para o Direito Comercial Internacional, que é um órgão subsidiário da Organização das Nações Unidas ONU, que tem por objetivo promo ver a unificação e harmonização do Direito Comercial Internacional. Deste último, também são utilizados pelo comércio internacional muitos contratos modelos não obrigató rios.

Mas, dentro deste contexto de pluralismo jurídico, Arnaud (1999) considera que existam graus de intervenções que reduzam o poder d os estados. A estes graus, ele denomina de direito estatal substituído, suprido ou suplantado.

No direito estatal substituído considera que o direito estatal interno encontra substitutos tanto à montante como à jusante. Ou sej a, tanto acima quanto abaixo de seu ponto tradicional. Acima tem-se os acordos regionais, como o NAFTA (Associação de Livre Comércio da América do Norte) e o MERCOSUL (MercadoComum do Sul). Abaixo, tem-se os movimentos de produção de direito privado, como ocorre com o caso da nova Lex Mercatória. Tanto uma forma quanto outra, importa em subtraçã o do poder estatal e afeta a sua soberania.

Quanto ao direito estatal suprido, resta configurado quando as políticas públicas ou programas de ação tomam a frente do direito tradici onal na regulação. Algumas destas políticas públicas não são regulação, mas possuem c unho distributivo, redistributivo e constitutivo. Há outras que sequer se ajustam às nomenclaturas tradicionais. Entre elas, tem-se as que tratam de clima, meio ambiente e relações ec onômicas internacionais. Todos estes assuntos não conseguem mais serem tratados isoladam ente, mesmo pelos próprios Estados. (ARNAUD, 1999) 
No direito estatal suplantado, o autor aponta o surgimento espontâneo de outras formas de regulação global, os quais fogem à regula ção estatal. É o caso do surgimento de novos mercados financeiros sem regras de organizaçã o externamente fixadas, ou até mesmo pré-fixadas. Nesta espontaneidade, fora de alcance dos tentáculos do Leviatã, ele se torna superado ou suplantado. Outro exemplo que pode ser tomado, é o poder regulamentar das organizações criminosas, que verdadeiramente suplan tam o Direito estatal.

Nesta classificação, verifica-se que em alguns caso s não se trata sequer de gradação da participação dos estados, pois elas sequer exist em, como no caso do direito estatal suplantado, que está completamente à margem do sistema tradicional de direito e regulação e se forma unicamente no meio privado.

No caso da Lex Mercatória, enquadra-se na classificação de direito estatal substituído, pois em parte de sua formação verifica -se a presença do Estado, mesmo que apenas na criação ou manutenção de algumas institui ções intergovernamentais, como é o caso do UNIDROIT e UNCITRAL. Assim, não se poderia class ifica-la como um direito suplantante, mas sim, substituto, alternativo.

Mas, também, não há como classificar aLex Mercatória como um direito estatal, porque de fato puramente não é. Então, ao menos converge-se para um entendimento, que ela seja um ordenamento paralelo ao estatal, especialmente pelo cunho internacional que tem, e é um meio normativo não convencional, alternativo, se ndo exercício de poder da classe mercante contra os entravados sistemas jurídicos estatais.

\subsection{O PODER CONFLITUAL E CONSENSUAL DA NOVA LEX MERCATÓRIA .}

Afinal de contas, o que os ordenamentos jurídicos representam? Normas de conduta? Fontes de direitos e obrigações? Estas e outras ind icações resumem-se em apenas uma palavra: Poder.

Existe um ditado popular que diz que "manda quem po de e obedece quem quer", mas ele está equivocado, pois, realmente, manda quem pode, mas obedece quem não tem poder. Ou manda quem tem poder e obedece quem tem menos poder.

Ressalta-se que o poder não está vinculado apenas à força militar ou a da economia, ele encontra várias configurações. Destaca Olsson (2014, p. 133) que "ao longo do tempo, diversos pensadores enfrentaram a questão do poder, sob óticas distintas, e tendo em conta 
realidades muito singulares." Desta forma, no prese nte estudo, também será abordado o poder em algumas de suas faces, no caso, o poder normativo.

Mas, quando se fala em poder normativo, também tem que se falar em governo e governança, já que o poder normativo, no mínimo advém de uma destas duas espécies de fenômenos sociais.

Foucault (1979), em uma passagem de sua obra afirma que as "leis, ordens, regulamentos, isto é, as armas tradicionais do soberano", são os principais instrumentos utilizados para o alcance de seus objetivos. Ou seja, o poder de um Estado dirigido por um governo é exercido por meio do direito positivo, principalmente na era do Estado Moderno.

Contudo, o exercício deste poder, pode estar condicionado por outros contrapoderes, ou poderes de resistência. Nos dizeres de Olsson 2007,( p. 362) "A relação de poder, por assim dizer, seria uma relação entre dois poderes, um 'maior' e outro 'menor'”. Todo poder encontrará uma certa resistência, mas o que determina se o poder menor prevalecerá sobre o poder maior, muitas vezes é a própria conveniênciado último.

E na seara do comércio internacional, estas afirmações ficam em evidência, como ocorre com a própria Lex Mercatória . Este direito nascido dentre os mercadores internacionais, pode perfeitamente ser classificado como um poder de resistência às ordens jurídicas estatais tradicionais. Contudo, seja por conveniência ou seja por verdadeira incapacidade, alguns estados nacionais a reconhecem perfeitamente, especialmente quando admitem à eleição da lei aplicável aos contratos; o utros preferem rejeitá-la, mas admitem a executividade de laudos arbitrais, onde pode igualmente ter sido aplicada a lei mercante, logo, haveria uma aceitação indireta.

Desta forma, a governança com e sem governo encampa da por Rosenau (2000) ganha relevo. Este autor esclarece que poder haver governo sem governança, bem como governança sem governo. Governança é algo mais ampl o que governo. Enquanto o governo está apoiado em uma autoridade formal, possui um poder formal, a governança está apoiada em objetivos comuns, seja ela formal ou informal, e que não necessite necessariamente de um poder de polícia para ser aceita e respeitada.

Novamente, vê-se que aLex Mercatória é o reflexo de um comércio internacional sem governo, mas não sem governança. Decorre, pois, de um poder não formal, não obrigatório, mas nem por isso deixa de ser reconhec ido e respeitado por um segmento internacional de grande importância, o comércio internacional. 
Contudo, esta governança do comércio internacional, o qual a Lex Mercatória é um reflexo, embora também seja um contrapoder ao monismo jurídico tradicional, seria conflitual ou consensual com a ordem jurídica estatal? Embora não haja uma linha bem definida entre as diferentes formas de poder, tampouco, poderes puros, esta classificação ajuda a elucidar o entrosamento entre os diversos atores no cenário internacional (OLSSON, 2014)

O autor acima explica que o poder conflitual, também chamado de "poder sobre", decorre da concepção weberiana de que dentro de um relacionamento social, existe a possibilidade de se realizar a vontade de um, em detrimento da vontade do outro, mesmo quando houver resistência, ou seja, mesmo contra sua vontade. Este poder pode ser exercido pelos sistemas repressivos estatais, como força mil itar e poder de polícia. Mas, pode ainda, ser exercido por meio da própria representação política, por meio de normas horizontais, hierarquizadas, de observância compulsória.

Já o poder consensual, também conhecido como "poder para”, que já era indiretamente relatado por Aristóteles e foi retoma do no Século XX por Parsons, tem como premissa o consenso, logicamente. O poder, assim, seria construído pelo diálogo até chegar-se a um consenso, sem a necessidade de "exclusão alter nativa de atores. Nessa linha, é possível que o poder de um não signifique a falta de poder d e outro." (OLSSON, 2014 p. 149).

Haugaard apud Olsson (2014), refere-se, ainda, que estas espécie de poder nem sempre são abertas, declaradas ou expressas, eles p odem ser tácitas. E isso também ganha implicância conforme o modelo político e jurídico d e cada Estado.

Considerando que há Estados que acatam aLex Mercatória quando aceitam a eleição da lei aplicável ao contrato, aqui parece nítida arelação consensual entre o poder estatal e o poder privado, pois um não exclui o outro. Assim, e m um contrato comercial internacional, poderiam as partes elegerem expressamente a aplicabilidade da Lex Mercatória em caso de solução de litígios.

Seria um contrassenso um poder admitir um direito se considerasse conflituoso consigo próprio. Desta forma, implicitamente fica e videnciado o caráter consensual e alternativo da Lex Mercatória . É claro que este caráter consensual trata-se de aspectos considerados preponderantes entre os diferentes sistemas, porque existe a questão da ordem pública estatal, que pode por alguns parênteses noconsenso.

Quando houver coincidência a ordem pública estatale as normas do ordenamento plural, não há que se falar em conflito, mas somente em consenso. Já o ponto sensível da 
discussão reside na hipótese de haver conflito entr e as normas do sistema privado e a ordem pública do sistema estatal. Nestes casos, tradicionalmente tem havido conflito entre os diversos poderes.

Mas, se o conflito acontecer, qual espécie normativa irá prevalecer? Aqui também há fatores a serem considerados, não podendo ser afirm ado em princípio que é o sistema estatal ou o sistema privado. Se o litígio for posto sob análise de um poder estatal, obviamente que a tendência deste poder será refutar normas que o contrariem naquilo que considerado inderrogável. Exceto quando este conflito se apresentar igualmente na ordem interna, hipótese pela qual será solucionado pela ponderação de princípios.

Situação diversa e mais complexa se apresenta quand o um Estado não admite a escolha do direito aplicável ao contrato. Neste caso, as partes contratantes ou fazem um malabarismo para inserirem o máximo possível de cláusulas contratuais correspondentes com o direito que gostariam ver aplicado, e, igualmente, ficam sujeitas a ordem pública do direito estatal, ou recorrem a um tribunal arbitral.

Na primeira hipótese, independentemente de qualquer coincidência normativa, a relação entre os diversos sistemas sempre será conflitivo, pois um ordenamento não admite o outro em seu interior de forma alguma. O mecanismo de superação deve ser dado com estribo na autonomia da vontade privada nas relações contra tuais, mas, até o limite da ordem pública e em complexos e inseguros contratos.

Por outro lado, nesta relação conflitual ente os di versos ordenamentos, a admissão da homologação de laudos arbitrais por parte dos siste mas estatais assume uma posição sui generis nesta relação de poder. O ordenamento estatal não admite qualquer outro direito além do seu, contudo, também não rediscute o mérito de decisão dos lautos arbitrais, sendo que por meio deles pode estar dando executividade a decisõe $\mathrm{s}$ baseadas em um direito altamente conflitivo com o seu.

Obviamente que a situação posta aparenta ser contra ditória. Há conflito ou á consenso entre estes poderes normativos? A resposta adequada ainda é que os poderes normativos assumem caráter preponderantemente conflituais ou minimamente consensuais.

Neste sentido, o mínimo de consenso reside no fato de que respeita-se a autonomia da vontade das partes contratantes desde que ela opte não pelo ordenamento jurídico aplicável, mas sim pela especialidade do órgão judicante, já que as câ maras arbitrais são inatas ao comércio. 
Observa-se que o respeito à autonomia da vontade, $\mathrm{s}$ e deve em razão da especialidade do órgão jurisdicional, pois não é qu alquer laudo ou julgado que é reconhecido pelo Estado, tem que ser necessariamente decorrente de um laudo de uma câmara arbitral devidamente reconhecida. Assim, mesmo que por consenso, vem à tona o poder de instituições privadas na criação normativa comercia 1 .

Desta forma, percebe-se nitidamente que há uma quebra da teoria monista, pois o próprio Estado direta ou indiretamente reconhece po deres normativas diferentes ao seu. A conclusão que se chega é que o Direito estatal e o Direito da Lex Mercatória pode ser preponderantemente consensual ou preponderantemente conflitual a depender da política interna de cada Estado, porque mesmo em raros momentos haverá consenso ou haverá conflito entre eles.

A exceção fica por conta dos Estados que não admite m eleição do direito aplicável ao contrato, tampouco reconhecem qualquer sentença arbitral. Aqui o conflito é intenso, existindo uma forma pura de poder conflitual.

Contudo, nem por isso a Lex Mercatória pode ser ignorada pelos juristas destes países, pois nada impede que as partes contratantes optem por levar seus litígios aos tribunais arbitrais. E como a grande maioria dos laudos são c umpridos voluntariamente, a Lex Mercatória está produzindo efeitos no interior destes ordenamentos estatais, em uma verdadeira demonstração de poder.

\section{CONCLUSÃO}

Após o presente estudo sobre o poder dos sistemas e statais e o poder da Lex Mercatória, verifica-se que a complexidade envolvida na sociedade internacional permite uma diversidade de posicionamentos didáticos a depender das particularidades de cada Estado.

Assim, a Lex Mercatória estudada de fronte com o ordenamento jurídico brasileiro, por exemplo, pode ganhar aspectos distintos da Lex Mercatória analisada paralelamente ao ordenamento jurídico Norte Americano ou Chinês.

Neste estudo preferiu-se classificar a Lex Mercatória como um poder preponderantemente conflitual ou preponderantemente consensual, já que as formas puras de poder são à exceção à regra. 
Também pode ser concluído que o pluralismo jurídico em tempos de globalização é algo inevitável, mesmo para os Estados mais conservadores. Verifica-se que, mesmo na posição de poder puramente conflitual, ainda assim, as partes contratantes terão uma segunda opção, sendo ela extraestatal. Mesmo que questionad a a necessidade do Estado para a execução de um laudo arbitral, existem sanções tamb ém de cunho extraestatal, não tradicionais, pois não usam da violência legítima, mas que também surtem efeitos, tema que foge ao presente trabalho.

Finalmente, também pode ser concluído que existem mecanismos para as partes que protagonizam o comércio internacional alcançarem os fins jurídicos desejados, mesmo em uma situação conflitual entre diversos ordenamentos jurídicos, basta que se antecipem as precauções necessárias logo na formação do contrato .

\section{REFERÊCIAS BIBLIOGRAFICAS.}

ARNAUD, André-Jean. O direito entre modernidade e globalização: Lições de filosofia do direito e do estado. Tradução Patrice Charles Wuillaume. Rio de Janeiro : Renovar, 1999.

BAPTISTA, Luiz Olavo. Contratos internacionais. São Paulo: Lex Editora, 2010.

BEDIN, Gilmar Antonio. A sociedade Internacional e o século XXI: em busca da construção de uma ordem judicial justa e solidária. Ijuí: Ed. Unijuí, 2001.

CARDOSO, Fernando Henrique; FALETTO, Enzo. Dependência e desenvolvimento na América Latina. 3.ed. Rio de Janeiro: Zahar, 1993.

COELHO, Luiz Fernando. Saudade do Futuro: Transmodernidade, direito e utopia. Florianópolis: Fundação Boiteux, 2001.

CORDEIRO, Douglas Alexander. A Lex Mercatória e as novas tendências de codificação do Direito do Comércio Internacional .Monografia (Bacharel em Direito) - Universidade Federal do Paraná, Curitiba, 2008.

DIMITRUK, Hilda Beatriz (Org). Cadernos Metodológicos: Diretrizes do trabalho científico. Chapecó: Argos, 2012.

FOUCAULT, Michel. Microfísica do poder. Tradução de Roberto Machado. 14 ed. Rio de Janeiro: Graal, 1979. 
GAMA JR., Lauro. Contratos Internacionais à luz dos Princípios do UN IDROIT 2004.

Rio de Janeiro: Renovar, 2006.

GLITZ, Frederico Eduardo Zedenin. Contrato, globalização e Lex Mercatória: Convenção de Viena 1980 (CISG), Princípios Contratuais Unidroit (2010) e Inconterms (2010). Rio de Janeiro: Clássica, 2012.

IANNI, Octavio. Teorias da Globalização. 3. ed. Rio de Janeiro: Civilização Brasileira, 1996.

KEOHANE, Robert O.; NYE, Joseph S.; Poder e independência: la política mundial en tansición. Trad. Heber Cardoso Franco. Buenos Aires: Grupo Editor Latinoamericano, 1988.

MONDAINI, Marco. Revolução Inglesa: o respeito aos direitos dos indivíduos. In: PINSKY, Jaime; PINSKY, Carla Bassanezi (orgs.). História da cidadania . 3. ed. São Paulo: Contexto, 2005.

MUÑOS, Edgardo; MOSER, Luiz Gustavo Meira. À adesão do Brasil à CISG Consequencias para o comércio da China e da AméricaLatina. 2012. Disponível em: <www.cisg-brasil.net/doutrina >. Acesso em: 04 jan. 2016.

OLIVEIRA, Odete Maria de. Teorias globais e suas revoluções: Impérios de poder e modos de produção. v.2, Ijuí: Ed. Unijuí, 2005.

OLIVEIRA, Renata Fialho de. Harmonização Jurídica no Direito Internacional. São Paulo: Quartier Latin, 2008.

OLSSON, Giovani. O poder Político no espaço global: o protagonismo d os atores estatais

e não estatais. In: OLIVEIRA, Odete Maria de (Org.). Relações Inte rnacionais, direito e poder. Ijuí: Unijuí, 2014.

, Giovani. Poder político e sociedade internacional: governanç a global com

e sem governo e desafios e possibilidades. Ijuí: Unijuí, 2007. 
ROSENAU, James N. Governança, ordem e transformação na política mundi al. In: ROSENAU, James N.; CZEMPIEL, Ernst-Otto (Orgs.). Governança sem governo: Ordem e transformação na política mundial. Trad. Sergio Bar th. Brasília: UNB, 2000.

SMITH, Adam. A riqueza das nações. São Paulo: Nova Cultural, 1996. Coleção os Economistas.

STRENGER, Irineu. Direito do Comércio Internacional e Lex Mercatória. São Paulo: LTr, 1996.

WOLKMER, Antonio Carlos. Pluralismo Jurídico: Fundamentos de uma nova cultura no

Direito. 3. ed. São Paulo: Alfa-Omega, 2001. 